\title{
The Profitability of Using Pegged Currencies in Carry Trade: A Case of Saudi Riyal
}

\author{
Musaed S. AlAli ${ }^{1}$, Lamya S. AlAli ${ }^{2} \&$ Fatema K. AlKhalifa $^{3}$ \\ ${ }^{1}$ School of Economics, Finance and Marketing, RMIT University, Melbourne, Australia. \\ ${ }^{2}$ College of Business Studies, Public Authority for Applied Education and Training, Kuwait. \\ 3 The Higher Institute of Telecommunication and Navigation, Public Authority for Applied Education and Training, \\ Kuwait. \\ Correspondence: Musaed S. AlAli, School of Economics, Finance and Marketing, RMIT University, Melbourne, \\ Australia.
}

Received: December 25, 2015

Accepted: January 9, 2016 Available online: January 15, 2016

doi:10.11114/aef.v3i1.1306

URL: http://dx.doi.org/10.11114/aef.v3i1.1306

\begin{abstract}
This paper examines the profitability of using pegged currencies in carry trade. Conducting this exercise on Saudi riyal against six floating currencies has proven to be very rewarding especially when enhanced with forecasting methods. Carry trade is a very popular currency speculation strategy among traders, where they borrow low-interest currencies and invest in high-interest currencies. It is a strategy that takes advantage of interest rate differentials between two currencies. Such strategy should not work under uncovered interest parity (UIP), since according to UIP high interest rate currencies should depreciate against low interest rate currencies by the interest rate differential itself. But studies have shown that UIP does not stand and carry traders are profiting from it. As a result of its failure, carry traders are making returns matching the returns of the S\&P 500 and outperforming it in terms of the Sharpe ratio.
\end{abstract}

Keywords: Carry Trade, Random Walk, Uncovered Interest Parity (UIP), Saudi Riyal (SAR).

\section{Introduction}

"Profitable and risky, but attractive" this is how La Marca (2007) describes carry trade. The simplicity of such strategy led many economists and practitioners such as Jorda and Taylor (2009) to consider it as a primitive and naïve trading strategy. But despite being labelled as a naïve strategy by many, Burnside et al. (2006), Dunis and Miao (2007), Moosa (2008), Darvas (2009), Menkhoff et al. (2012), and Jurek (2014) all confirm that carry trade does not only produce similar returns to the of the S\&P 500, but it is also less risky, generating better Sharpe ratio (Gyntelberg and Remolona, 2007). Brunnermeier and Pedersen (2009) found that carry trade returns are much less variable than stock returns, with an annualized standard deviation of about 5 percent (compared to about 15 percent for stocks); as a result, the Sharpe ratio of the carry trade is double that of stocks. A study conducted by Burnside et al. (2007) for the period 1997 to 2006 , where they used the U.S. dollar as the funding currency in carry trade,- they concluded that carry trade is a profitable strategy generating an annualized Sharpe ratio of 1.32 compared to 0.23 for the U.S. stock market. Gyntelberg and Remolona (2007) show that the annualised average daily return on the Australian dollar/yen carry trade was $12.5 \%$ per year during the period September 2001 to September2007, compared to 3.6\% for the S\&P 500 index. Neely and Weller (2013) stated that there is a growing body of literature indicating that carry trade have statistically and economically significant positive excess returns and a Sharpe ratio about double that of equity markets.

UIP is an arbitrage condition indicating that no profit opportunity should arise from the interest rate differential between two currencies. According to UIP, a low interest rate currency should appreciate against the high interest rate currency by the interest rate differential itself. However, this is not the case. It has been noticed that currencies with higher interest rates tend to appreciate against low interest rate currencies, contradicting UIP. The success of carry trade is a result of the failure of uncovered interest rate parity (UIP). Baillie and Chang (2011) described carry trade as a speculation against UIP, while Gyntelberg and Remolona (2007) described it as nothing more than a bet against UIP. Although many researchers, such as Gyntelberg and Remolona (2007), Baillie and Chang (2011), and others, tend to imply a link between the failures of UIP and profitability, Moosa and Halteh (2012) state that, although the failure of UIP is a necessary condition for a profitable carry trade, it is not a sufficient enough condition. They argue that big 
movements in the currency markets which satisfy the failure of UIP might wipe out the interest rate differential and even produce a losing position.

Literature shows that carry trade flourishes during the periods of high interest rate differential and low exchange rate volatility. Galati et al. (2007) provided evidence indicating that foreign exchange trade volumes are positively correlated with higher domestic interest rates. Hattori and Shin (2007) found evidence indicating that volumes in carry trades involving the yen are higher when interest differentials against the yen are high. Jylha and Suominen (2011) found that the number of speculators increases as the interest rate differential goes higher. But being a leveraged strategy as described by Sy and Tabarraei (2009), any swing in the exchange rates would result in igniting stop loss orders adding to the momentum of the exchange rate move resulting in further losses for traders. That's why predicting currency crashes is crucial for carry traders. Embedding a forecasting element into the carry trade decision-making process could reduce the exchange rate risk, enhance profitability and improve risk-adjusted returns, as concluded by Jorda and Taylor (2009), Moosa (2010), Schmidbauer et al. (2010), Li (2011), Moosa and Halteh (2012), and others. For instance, Della Corte et al. (2009) documented that there is a significant economic benefit to an investor who exploits deviations from UIP by forecasting currency returns. $\mathrm{Li}$ (2011) found that the profitability and risk-return measures can be improved when the selection process is enhanced with a forecasting element. Also, Bhatti (2012) found that, other than the interest rate differential, the expected change in the exchange rate over the investment holding period is an important factor in determining the return on carry trade. Moosa and Halteh (2012) also stated that the interest rate differential is not a good indicator for carry trade return.

The magnitude of error was used by Meese and Rogoff (1983) to evaluate the reliability of the forecasting model. With the inability to beat such criteria, a conclusion was drawn among researchers and practitioners that professional forecasts would work just as well as a naïve forecasting model if not worse. This pessimistic effect on the field of exchange rate modelling led many such as Fair (2008) to describe exchange rate equations as "not the pride of open economy macroeconomics" and argue that the "general view still seems pessimistic". But, Chow et al. (2007) questioned the soundness of using such measures to evaluate the forecasting model by stating, "It seems irrational for profit-maximizing firms to 'waste' millions of dollars generating and buying professional forecasts". As a result of their findings, they suggested that it might not be suitable to judge the quality forecasting models using forecast error measures, but rather use profit as a judging criterion. Cheung et al. (2005) noted that using criteria other than the mean square error (MSE) is not "changing the rules of the game" and minimizing the mean square error may not be important from an economic standpoint, implying that relying on mean square error may result in overlooking other important aspects of prediction, such as profitability.

Since the failure of beating Meese and Rogoff's (1983) magnitude of error criteria, researchers have been exploring new measures to evaluate the forecasting models. Boothe and Glassman (1987) compared exchange rate forecasting models using two different criteria: accuracy (measured by the root mean square error) and profitability. They conclude that there is no obvious relationship between accuracy measures and profitability. Further, a strong relation between direction accuracy and profitability was found but not between error measures and profitability as concluded by Leitch and Tanner (1991). They argued that direction accuracy may be more relevant for profitability than error measures and that measuring the forecasting accuracy based on the magnitude of the error has no predictable relation to profitability. Engle and Hamilton (1990) supported the use of direction accuracy, by describing it as "not a bad proxy for a utility-based measure of forecasting performance". Moosa and Burns (2012) support that view by stating that profitability is consistently related to direction accuracy while the random walk does not predict the direction. Moosa (2013) suggested that profitability is the ultimate test of forecasting accuracy.

\section{Methodology}

Two strategies will be examined in this paper. The first strategy is the conventional carry trade that is based only on the interest rate differential, and the second is a forecasting-based strategy that takes both the interest rate differential and the forecasted exchange rate into consideration.

Let $i_{x}$ and $i_{y}$ be the interest rates for currencies $x$ and $y$, respectively. In addition, let $S$ be the spot rate between the two currencies measured as one unit of $y$ against $x$, so appreciation of $y$ against $x$ would result in a higher $S$, and vice versa.

Under carry trade, when $i_{y}>i_{x}$ then:

1. At time $t$, the carry trader would borrow $x$ at $i_{x}$ for the period $t$ to $t+1$.

2. That amount borrowed is converted to $y$ at $S_{t}$, obtaining $1 / S_{t}$ units of $y$. This amount is invested at $i_{y}$ for the period $t$ to $t+1$.

3. At $t+1$, the $y$ value of the investment will be $\left(1 / S_{t}\right)\left(1+i_{y}\right)$. 
4. The $x$ currency value of the investment, converted at the spot rate prevailing at $t+1$, is

$\left(S_{t+1} / S_{t}\right)\left(1+i_{y}\right)$.

5 . At $t+1$, the loan on $x$ matures, and the amount $\left(1+i_{x}\right)$ has to be repaid.

In this case the return on carry trade is given by;

$$
\pi=\frac{s_{t+1}}{s_{t}}\left(1+i_{y}\right)-\left(1+i_{x}\right)
$$

which can be rewritten as

$$
\pi=\left(i_{y}-i_{x}\right)+\dot{S}_{t+1}
$$

where $\dot{S}_{t+1}$ is the percentage change in the exchange rate between $t$ and $t+1$. The carry trade operation is implicitly based on the assumption of a random walk without drift (Moosa, 2004), which means that $\dot{S}_{t+1}=0$. Thus, carry trade is profitable as long as $\left(i_{y}-i_{x}\right)>-\dot{S}_{t+1}$. (That is, as long as the interest rate differential is larger than the depreciation of currency $y$ against currency $x$.)

Because of the changes in interest rates differential, it is necessary to switch the role of the currencies, so the general formula for calculating the rate of return on the carry trade will be as follows:

$$
\pi=\left\{\begin{array}{lll}
\left(i_{y}-i_{x}\right)+\dot{S}_{t+1} & \text { if } & i_{y}>i_{x} \\
\left(i_{x}-i_{y}\right)-\dot{S}_{t+1} & i_{y}<i_{x}
\end{array}\right.
$$

The forecasting-based strategy involves calculating the expected rate of return and conducting the position accordingly. The expected return is calculated as follows:

$$
\pi^{e}=\left(i_{y}-i_{x}\right)+\dot{S}_{t+1}^{e}
$$

Where $\dot{S}_{t+1}^{e}$ is the calculated percentage change in exchange rate based on the forecasting model. Thus, we go long $y$ and short $x$ if $\pi^{e}>0$ and vice versa. In that case, the profitability of the forecasting-based strategy is as follows:

$$
\pi=\left\{\begin{array}{lll}
\left(i_{y}-i_{x}\right)+\dot{S}_{t+1} & & \pi^{e}>0 \\
\left(i_{x}-i_{y}\right)-\dot{S}_{t+1} & \text { if } & \pi^{e}<0
\end{array}\right.
$$

Since the Saudi riyal is pegged to the U.S. dollar at 3.75 riyals per dollar, with a very narrow fluctuation band, the exchange rate of the riyal will reflect the economic conditions of the U.S. dollar. Thus, when calculating for $\dot{S}_{t+1}^{e}$ using Frenkel-Bilson flexible price monetary model of exchange rates, we will be doing so for the U.S. dollar.

$$
s_{t}=\alpha_{0}+\alpha_{1}\left(m_{a, t}-m_{b, t}\right)+\alpha_{2}\left(y_{a, t}-y_{b, t}\right)+\alpha_{3}\left(i_{a, t}-i_{b, t}\right)+\varepsilon_{t},
$$

where $s$ is the natural log of the exchange rate, $m$ is the natural log of the money supply, $y$ is the natural log of the industrial production, $i$ is the nominal interest rate, $\varepsilon$ is the error factor, and $a$ and $b$ refer to the countries whose currencies are involved. Here, country $b$ will have its currency as the base currency in the exchange rate pair. The forecasted exchange rate will be as follows:

$$
\hat{s}_{t+1}=\hat{\alpha}_{0}+\hat{\alpha}_{1}\left(m_{a, t+1}-m_{b, t+1}\right)+\hat{\alpha}_{2}\left(y_{a, t+1}-y_{b, t+1}\right)+\hat{\alpha}_{3}\left(i_{a, t+1}-i_{b, t+1}\right),
$$

Where $\hat{\alpha}_{0}$ is the estimated value of $\alpha_{0}$ and so on. To convert the natural log forecasted exchange rate to the estimated exchange rate, the following is applied:

$$
S_{t+1}^{e}=\exp \left(\hat{s}_{t+1}\right)
$$

$\dot{S}_{t+1}^{e}$ is calculated from $S_{t+1}^{e}$ and $S_{t}$, which can be used to calculate the expected return in equation (4).

\section{Data and Empirical Results}

The empirical results presented in this paper are based on six currency combinations involving the Saudi riyal (SAR) against the Japanese yen (JPY), the British pound (GBP), the Korean won (KRW), the Singaporean dollar (SGD), the Canadian dollar (CAD), and the Swiss franc (CHF). Monthly data were used for the period of January 2001 to December 2011. Data were obtained from the International Financial Statistics (CD-ROM) and the DataStream terminal.

Following Meese and Rogoff (1983) the magnitude of error measures were used to evaluate the forecasting model against the random walk. Table 1 show that the monetary model was unable to beat the random walk in any pair. The error measuring criteria for the average of the six pairs is shown in table 2. By looking at the mean absolute error (MAE) 
for both strategies, it is 1.78 for the carry trade compared to 7.27 for the forecasting-based model. The mean square error (MSE) is 6.87 for the carry trade while, for the forecasting-based model, it is 92.4. In terms of RMSE, the results were 2.52 and 9.42 for the random walk and forecasting-based models, respectively. The Theil inequality coefficient (U) concludes the findings in one number, confirming the supremacy of the random walk over forecasting models by showing no result below 1 . The same results can be seen at the individual pairs, where none of the individual pairs out-performed the random walk in all error measures.

Table 1. Results for Individual Pairs

\begin{tabular}{|c|c|c|c|c|c|c|c|c|c|c|c|c|}
\hline & \multicolumn{2}{|c|}{ SGD/SAR } & \multicolumn{2}{|c|}{ SAR/GBP } & \multicolumn{2}{|c|}{ JPY/SAR } & \multicolumn{2}{|c|}{ SAR/KRW } & \multicolumn{2}{|c|}{ CAD/SAR } & \multicolumn{2}{|c|}{ CHF/SAR } \\
\hline & $\mathrm{CT}$ & $\mathrm{FC}$ & $\mathrm{CT}$ & $\mathrm{FC}$ & $\mathrm{CT}$ & $\mathrm{FC}$ & $\mathrm{CT}$ & $\mathrm{FC}$ & $\mathrm{CT}$ & $\mathrm{FC}$ & $\mathrm{CT}$ & $\mathrm{FC}$ \\
\hline MAE & 1.1 & 4.5 & 1.6 & 6.3 & 2.0 & 7.7 & 2.1 & 8.4 & 1.4 & 6.9 & 2.5 & 9.8 \\
\hline MSE & 2.2 & 40.2 & 4.6 & 68.4 & 6.4 & 86.3 & 14.1 & 111.9 & 3.6 & 90.7 & 10.3 & 156.9 \\
\hline RMSE & 1.5 & 6.3 & 2.2 & 8.3 & 2.5 & 9.3 & 3.8 & 10.6 & 1.9 & 9.5 & 3.2 & 12.5 \\
\hline $\mathrm{U}$ & 4.2 & & 3.77 & & 3.72 & & 2.79 & & 5.00 & & 3.91 & \\
\hline Ave Interest Diff & 3.48 & & 1.56 & & 4.68 & & 3.60 & & 3.00 & & 3.84 & \\
\hline Direction Accuracy \% & & 55.31 & & 50.28 & & 50.84 & & 60.89 & & 48.60 & & 55.87 \\
\hline Confusion Rate \% & & 44.69 & & 49.72 & & 49.16 & & 39.11 & & 51.40 & & 44.13 \\
\hline Mean Return & 2.01 & 2.14 & 2.24 & -0.61 & 0.90 & 3.76 & -0.02 & 10.80 & 0.42 & 1.47 & 0.84 & 1.39 \\
\hline Cumulative Return & 32.17 & 34.89 & 33.94 & -12.45 & 7.78 & 65.35 & -13.37 & 345.58 & 3.13 & 20.66 & 3.36 & 12.17 \\
\hline Standard Deviation & 18.1 & 18 & 26.4 & 26.04 & 30.72 & 30.48 & 45.24 & 43.92 & 22.92 & 22.80 & 38.76 & 38.64 \\
\hline Sharpe Ratio & 0.11 & 0.12 & 0.08 & -0.02 & 0.03 & 0.12 & 0.00 & 0.25 & 0.02 & 0.06 & 0.02 & 0.04 \\
\hline VaR $99 \%$ & 3.53 & 3.93 & 5.64 & 5.62 & 6.09 & 4.72 & 11.56 & 5.31 & 4.76 & 4.20 & 6.33 & 6.32 \\
\hline VaR $95 \%$ & 1.77 & 2.07 & 3.39 & 3.93 & 4.26 & 3.66 & 4.37 & 3.10 & 2.87 & 2.57 & 4.97 & 4.62 \\
\hline
\end{tabular}

$\mathrm{CT}$ is carry trade and FC is the forecasting based strategy.

When it comes to measures of return, it can be seen that carry trade generated positive mean returns in five out of the six pairs; while, the forecasting-based strategy also produced five pairs with positive mean returns. SAR/GBP generated the highest mean return of $2.24 \%$ in carry trade; while, SAR/KRW showed the biggest return of $10.80 \%$ in the forecasting-based strategy. The only pair that showed negative return was SAR/KRW in carry trade and SAR/GBP for the forecasting-based strategy. Looking at carry trade average mean return for the six pairs it was $1.065 \%$, compared to $3.16 \%$ for the forecasting-based strategy. When embedding the forecasting model into the selection process, five of the six pairs showed improvements in mean return, except for SAR/GBP where the mean return for carry trade surpassed the mean return of the forecasting-based strategy. In regard to the relation between interest rate differential and mean return. The results were consistent with Moosa (2008) and Moosa and Halteh (2012) that higher interest rate differential do not necessarily mean a higher return. It can be seen from the results that while JPY/SAR had the largest interest rate differential, it didn't produce the highest mean return. Adding to it, while SAR/KRW had an interest rate differential of $3.60 \%$, it generated a negative mean return. In terms of cumulative return, the forecasting-based strategy outperformed the carry trade in five out of the six pairs, except for SAR/GBP, where carry trade produced a better cumulative return. The pair that produced the highest cumulative return under the carry trade was SAR/GBP, with $33.94 \%$, while SAR/KRW produced an astounding cumulative return of $345.58 \%$, up from $-13.37 \%$ under the carry trade. This huge gain in SAR/KRW was a result of the high volatility in the exchange rate of the Korean won during the 1997 Asian financial crisis. The forecasting model was able to capture most of these movements resulting in the huge improvement in cumulative return.

Looking at the volatility, carry trade had a mean standard deviation for the six pairs of 30.36 compared to 29.98 for the forecasting-based strategy. SAR/KRW showed the highest standard deviation in both the carry trade and the forecasting-based strategy, with 45.24 and 43.92, respectively. By looking at the Sharpe ratio, it can be seen that the Sharpe ratio has improved under the forecasting-based strategy in five out of the six pairs, with SAR/KRW being the most improved among all pairs. Under carry trade, the average Sharpe ratio for the six pairs was 0.043 while that 
average improved to 0.095 under the forecasting-based strategy.

Table 2. Cumulative Results

\begin{tabular}{ccc}
\hline & CT & FC \\
\hline MAE & 1.78 & 7.27 \\
MSE & 6.87 & 92.4 \\
RMSE & 2.52 & 9.42 \\
U & \multicolumn{2}{c}{3.90} \\
Ave Interest Diff & \multicolumn{2}{c}{3.36} \\
Direction Accuracy & \multicolumn{2}{c}{$53.63 \%$} \\
Confusion Rate & \multicolumn{2}{c}{$46.37 \%$} \\
Mean Return & 1.065 & 3.16 \\
Cumulative Return & 11.17 & 77.70 \\
Standard Deviation & 30.36 & 29.98 \\
Sharpe Ratio & 0.043 & 0.095 \\
VaR 99\% & 6.32 & 5.01 \\
VaR 95\% & 3.605 & 3.325 \\
\hline
\end{tabular}

Regarding direction accuracy, it can be seen from the results that the forecasting-based strategy produced five pairs with an accuracy level of more than 50\% and only one pair, CAD/SAR, with an accuracy level of less than 50\%. When associating direction accuracy to mean returns it can be seen that four out of the five pairs with accuracy rates above $50 \%$ showed an improvement to their mean returns; the only pair that did not was SAR/GBP. On the other side, despite having direction accuracy that is less than 50\%, CAD/SAR showed an improvement in mean return. This result tends to contradict Leitch and Tanner's (1991) finding that there is a strong relation between direction accuracy and profitability.

When it comes to value-at-risk (VaR) at the 99\% confidence level, five out of the six pairs showed improvement when carry trade was enhanced with a forecasting element. SAR/KRW had the most improvement, from $11.56 \%$ to $5.31 \%$, while SGD/SAR was better off in carry trade. At the 95\% confidence level, four out of the six pairs showed an improvement in VaR, while SGD/SAR and SAR/GBP were the only two pairs with a higher expected loss in the forecasting-based model than in carry trade model. When comparing the two strategies, the forecasting-based strategy improved the average VaR at both the $99 \%$ and the $95 \%$ confidence level. At the $99 \%$ confidence level the average for the six pairs declined from $6.32 \%$ to $5.01 \%$, while at the $95 \%$ confidence level, the average went down from $3.605 \%$ to $3.325 \%$.

When comparing carry trade to the S\&P 500 as shown in table 3, the results show that the mean return on carry trade was lower than the return on the S\&P 500. For the sample period carry trade produced an average mean return for the six pairs of $1.065 \%$ compared to $1.875 \%$ for the S\&P 500. On the other hand, carry trade demonstrated lower volatility than the stock market which is consistent with Brunnermeier and Pedersen (2009) findings. When it comes to the Sharpe ratio, it can be seen that carry trade produced a better Sharpe ratio of 0.043 compared to 0.034 for the S\&P 500 . This finding is consistent with Burnside et al (2007) findings that carry trade produces better Sharpe ratio than the S\&P 500 .

Table 3. Comparative Results between Carry Trade and S\&P 500

\begin{tabular}{ccc}
\hline & CT & S\&P 500 \\
\hline Mean Return & 1.065 & 1.872 \\
Standard Deviation & 30.36 & 54.72 \\
Sharpe Ratio & 0.043 & 0.034 \\
VaR 99\% & 6.32 & 10.1 \\
VaR 95\% & 3.605 & 6.995 \\
\hline
\end{tabular}

\section{Conclusion}

The results presented in this paper in using pegged currencies in carry trade were consistent with AlAli and AlKulaib (2015) findings that pegged currencies can be used in carry trade with encouraging results. This paper demonstrated that the use of the Saudi riyal in a carry trade, in its simplest form, can generate positive returns with a better Sharpe ratio than the S\&P 500 confirming the findings of Gyntelberg and Remolona (2007), Brunnermeier and Pedersen (2009) and others. Adding forecasting techniques into the selection process led to an improvement in both profitability and the risk-adjusted return. Using six currency combinations, with the Saudi riyal in each one of the pairs, a profit was made in five of the six pairs when interest rate differential was the sole selection criterion. The number of profitable pairs stayed 
the same when a forecasting technique was introduced, but the profitability and risk-adjusted return were improved. We also conclude that the interest rate differential is not associated with profit, confirming the findings of Moosa (2008) and Moosa and Halteh (2012). On the other hand, we were unable to establish a relation between direction accuracy and profitability.

The findings of this paper also support Meese-Rogoff (1983) who found that no forecasting model can outperforms the naïve random walk in terms of the magnitude of error measurements such as root mean square error. But, in terms of profitability and risk-adjusted returns, the monetary model showed that it performs well in generating better returns than random walk. These results answer the question of Chow et al. (2007) regarding the reason behind the huge amount of money paid by profit-maximizing firms to purchase forecasting models.

\section{References}

AlAli, M., \& AlKulaib, Y. (2015). Carry Trade Profitability Using Pegged Currency: A Case of the Qatari Riyal. International Journal of Economics and Finance, 7(10), 215-221. http://dx.doi.org/10.5539/ijef.v7n10p215

Baillie, R., \& Chang, S. (2011). Carry Trades, Momentum Trading and the Forward Premium Anomaly. Journal of Financial Markets, 14(3), 441-464. http://dx.doi.org/10.1016/j.finmar.2011.01.001.

Bhatti, R. (2012). On Return and Risk in Carry Trades: A Case of the Pak Rupee. International Journal of Economic and Finance Studies, 4(2), 201-214.

Boothe, P., \& Glassman, D. (1987) Comparing Exchange Rate Forecasting Models: Accuracy versus Profitability, International Journal of Forecasting, 3, 65-79. http://dx.doi.org/10.1016/0169-2070(87)90079-3

Brunnermeier, M., \& Pedersen, L. (2009). Market Liquidity and Funding Liquidity. Review of Financial studies, 22(6), 2201-2238. http://dx.doi.org/10.1093/rfs/hhn098.

Burnside, C., Eichenbaum, M., Kleshchelski, I., \& Rebelo, S. (2006). The Returns to Currency Speculation. NBER Working Paper, 12489. Cambridge, MA: National Bureau of Economic Research.

Burnside, C., Eichenbaum, M., Kleshchelski, I., \& Rebelo, S. (2007). The Returns to Currency Speculation in Emerging Markets, NBER Working Paper, 12916. Cambridge, MA: National Bureau of Economic Research. http://dx.doi.org/10.1257/aer.97.2.333.

Cheung, Y., Chinn, M., \& Garcia, A. (2005). Empirical Exchange Rate Models of the Nineties: Are Any Fit to Survive, Journal of International Money and Finance, 24, 1150-1175. http://dx.doi.org/10.1016/j.jimonfin.2005.08.002.

Chow, K., \& Tan, K. L. Y. (2007). The Use of Profits as Opposed to Conventional Forecast Evaluation Criteria to Determine the Quality of Economic Forecasts. Singapore: Nanyang Business School, Nanyang Technological University.

Darvas, Z. (2009). Leveraged Carry Trade Portfolios. Journal of Banking and Finance, 33(5), 944-957. http://dx.doi.org/10.1016/j.jbankfin.2008.10.007.

DellaCorte, P., Sarno, L., \& Tsiakas, I. (2009). An Economic Evaluation of Empirical Exchange Rate Models. Review of Financial Studies, 22, 3491-3530. http://dx.doi.org/10.1093/rfs/hhn058.

Duni, C., \& Miao, J. (2007). Trading Foreign Exchange Portfolios with Volatility Filters: The Carry Trade Model Revisited. Applied Financial Economics, 17(3), 249-255. http://dx.doi.org/10.1080/09603100500447578.

Fair, R. (2008). Estimating Exchange Rate Equations Using Estimated Expectations, Yale University ICF Working Paper, 07-18.

Galati, G., Heath, A., \& McGuire, P. (2007). Evidence of Carry Trade Activity, BIS Quarterly Review, 27-41.

Gyntelberg, J., \& Remolona, E. (2007). Risk in Carry Trade: A Look at Target Currencies in Asia and the Pacific. BIS Quarterly Review, 4, 73-82.

Hattori, M., \& Shin, H. (2007). The Broad Yen Carry Trade, Institute for Monetary and Economic Studies Paper, No. 07-E-19, Bank of Japan.

Jorda, O., \& Taylor, A. (2009). The Carry Trade and Fundamentals: Nothing to Fear but FEER Itself, NBER Working Paper, 15518, Cambridge, MA: National Bureau of Economic Research. http://dx.doi.org/10.1016/j.jinteco.2012.03.001.

Jurek, J. (2014). Crash-neutral Currency Carry Trades. Journal of Financial Economics, 113(3), 325-347. http://dx.doi.org/10.1016/j.jfineco.2014.05.004.

Jylhä, P., \& Suominen, M. (2011). Speculative Capital and Currency Carry Trades. Journal of Financial Economics, 99(1), 60-75. http://dx.doi.org/10.1016/j.jfineco.2010.07.006. 
LaMarca, M. (2007). Carry trade and financial fragility. Coping with globalized finance: recent challenges and long term perspectives. UNCTAD/GDS/2007/2, United Nations, Geneva and New York.

Leitch, G., \& Tanner, J. (1991). Economic Forecast Evaluation: Profit Versus the Conventional Error Measures. American Economic Review, 81, 580-590.

Li, M. (2011). An Evaluation of Exchange Rate Models by Carry Trade. Journal of Economics and International Finance, 3, $72-87$.

Meese, R., \& Rogoff, K. (1983). Empirical Exchange Rates Models of the Seventies: Do They Fit Out of Sample? Journal of International Economics, 14, 3-24. http://dx.doi.org/10.1016/0022-1996(83)90017-X.

Menkhoff, L., Sarno, L., Schmeling, M., \& Schrimpf, A. (2012). Carry Trades and Global Foreign Exchange Volatility. Journal of Finance, 67(2), 681-718. http://dx.doi.org/10.1111/j.1540-6261.2012.01728.x.

Moosa, I. (2004). What Is Wrong with Market-Based Forecasting of Exchange Rates? International Journal of Business and Economics, 3(2), 107-121.

Moosa, I. (2008). Risk and Return in Carry Trade. Journal of Financial Transformation, 22(3), 8-13.

Moosa, I. (2010). The Profitability of Carry Trade. Economia Internazionale, 63, 261-380.

Moosa, I. (2013). Why Is It so Difficult to Outperform the Random Walk in Exchange Rate Forecasting?. Journal of Applied Economics, 45, 3340-3346. http://dx.doi.org/10.1080/00036846.2012.709605.

Moosa, I., \& Burns, K. (2012). Can Exchange Rate Models Outperform the Random Walk? Magnitude, Direction and Profitability as Criteria. Journal of International Economics (Economia Internazionale), 65(3), 473-490.

Moosa, I., \& Halteh, P. (2012). The Profitability of Carry Trade Relative to a Forecasting-Based Strategy. Journal of International Economics, 65(4), 605-621.

Neely, C., \& Weller, P. (2013). Lessons from the evolution of foreign exchange trading strategies. Journal of Banking and Finance, 37(10), 3783-3798. http://dx.doi.org/10.1016/j.jbankfin.2013.05.029

Schmidbauer, H., Rösch, A., Sezer, T., \& Tunalıglu, V. (2010). Currency Carry Trading with MGARCH Based Carry-to-Risk Portfolio Optimization. Proceedings of the 30th International Symposium on Forecasting ISF2010, San Diego, June 20-23.

Sy, M., \& Tabarraei, H. (2009). Carry Trade and Return Crash Risk. Paris School of Economics, Working Paper.

\section{(cc) EY}

This work is licensed under a Creative Commons Attribution 3.0 License. 